\title{
SELF-ASSESSMENT TO SUBJECTIVE CREATIVITY AND NEW IDEAS: DETERMINANT WITHIN RISK TAKING, AUTONOMY AND TRADITION
}

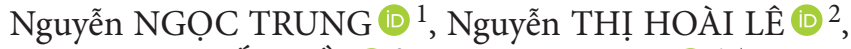 \\ Trần VIẾT HỒI (10 ${ }^{3}$, Won Joong KIM (1) 4,* \\ 1, 2 Department of Human Development and Human Resource Studies, Institute of Human Studies, \\ Vietnam Academy of Social Sciences, No. 9 Kim Ma Thuong str., Ba Dinh, Ha Noi-Vietnam 100000, \\ Hanoi, Vietnam \\ ${ }^{3}$ Center for Enterprise Partnership, Hanoi University of Industry, No. 298 Cau Dien str., \\ Bac Tu Liem, Hanoi 100000, Vietnam
}

${ }^{4}$ Department of Economics, Konkuk University, 120 Neungdong-ro, Gwangjin-Gu, Seoul 05029, South Korea

Received 29 September 2020; accepted 2 February 2021

\begin{abstract}
Individuals' creativity and new ideas today are not only essential for firms, agencies or organizations but also indispensable even for a nation. This article analyzes impacts of autonomy, risk taking and, especially, factor of tradition on self-assessment to subjective creativity and attitude to new ideas. Specifically, the article empirically analyzes how those factors affect creativity and new ideas and tests whether tradition is more meaningful than others in explaining creativity or new ideas. Most of previous research has theoretically concluded that, because of rigid and unchangeable norms and rules in tradition, individuals are not easy to generate or do new things, especially in Eastern countries. South Korea, with a long tradition within Asian and Confucian values, it is said that these values may limit creativity and new ideas. However, South Korea has achieved satisfactory outcomes in process of creative development, which could positively be affected by its tradition. Using the data from World Values Survey for South Korea at the latest wave 6th, the results show that tradition has a positive impact on subjective creativity beside significantly positive influence of risk taking, which is not considered to be important from cultural perspective.
\end{abstract}

Keywords: autonomy, Confucianism, creativity, new ideas, risk taking, tradition.

\section{Introduction}

Creativity and new ideas are not only essential for agencies or entrepreneurial organizations but also paramount for one region or even one country. Kristeller (1983) believes that achieving creative works, novelties or human endeavors is not only affected by social changes but also by tradition and originality, which are big-league elements to the above things. Besides,

${ }^{\star}$ Corresponding author. E-mail: wjkim72@konkuk.ac.kr

Copyright (c) 2021 The Author(s). Published by Vilnius Gediminas Technical University

This is an Open Access article distributed under the terms of the Creative Commons Attribution License (http://creativecommons. org/licenses/by/4.0/), which permits unrestricted use, distribution, and reproduction in any medium, provided the original author and source are credited. 
Cho et al. (2018) confirm characteristics from a country or region may affect creative classes: in other words, cultural background and regional development level can also generate new creative and cultural industries. The authors also conclude that creative and cultural novelties in some Asian nations, due to their long history of tradition, contain a huge potential to grow soon compared with Western countries.

On the other hand, Baucus et al. (2008) conclude that tradition is a system of common values, norms and beliefs and terms of rules and regulations. Individuals may dismiss tradition to generate new ideas and innovative thoughts. They may believe that they will not achieve success if they follow rigid traditional norms. However, when investigating the success of creative economies with a high level of wealth and many innovative materials, Murphy (2012) suggests that researchers should analyze factors like culture or tradition that fosters or nurtures creative economies and explore how creative economies are affected by that. South Korea (SK) has a long traditional culture with shared Asian values, so-called conservatism and Confucianism and has been gaining many achievements in process of development with creative activities. Perhaps, traditional values have played decisive roles in that process as many researchers adapting Hofstede's cultural dimensions theory find that positive relationship between individualism and creativity of a nation does not come out without consideration of traditional norms (Rinne et al., 2013). One of the key engines for the success of SK is believed to be cultural values so that, if any research can provide strong evidence of positive causality from tradition to creativity, then leaders in other organizations or nations will try to develop their own tradition further to enhance the creativity of their members. Also, it could provide a deeper view and further understanding of the role of tradition for both local policy makers and government officials in small units.

There have been many studies focusing the influence of culture on creativity mostly in theoretical perspectives (Amabile, 1998; Amabile et al., 1996; Brindley, 2008; Bye \& Sohn, 2010). However, not many studies have been empirically analyzed the causal effects of culture and tradition on creativity. To check this standpoint, the present research is to test how subjective creativity and attitude to new ideas can benefit from individual traits of autonomy, risk taking, routine task and tradition. Furthermore, this study also checks whether tradition is more important than the preceding variables or demographic factors in explaining creativity in SK.

\section{Literature background}

\subsection{Role of autonomy on creativity}

First of all, nature and strength between autonomy and creativity depend on moderating factors such as prior task experience, a shift in task condition and self-control. Benefit to creativity from autonomy occurs only if individuals have enough necessary skills, experience and self-control (Chang et al., 2012). On the other hand, Schwartz (1999) divides autonomy into intellectual autonomy and affective autonomy of which intellectual autonomy is related to individuals who pursue their own ideas and intellectual trends. Likewise, intellectual autonomy is perhaps conducive to creativity since it advocates individuals' mind, which is certainly based on their culture. 
From practical implications of Volmer et al. (2012), the authors suggest that leader-member exchange is positive with creativity and that relationships can be flourished if individuals are granted job autonomy. The authors also posit job autonomy creates a culture for determining the pace and consequent method for finishing tasks beyond organizational restrictions or constraints. In addition, from a theoretical view, DiLiello and Houghton (2006) suggest that individuals with strong self-leadership will have more innovation and creativity potentials than those with weak self-leadership. Correspondingly, individuals with strong self-leadership will practice innovation and creativity more if they receive strong support at work. Furthermore, investigating ties between supervisor and subordinate, Wang and Cheng (2010) find that both creative role identity and job autonomy show a significant and positive relationship with creativity and when the job autonomy is high, the link between benevolent leadership and creativity becomes more effective. In sum, it may be that autonomy is very important for creativity.

\subsection{Risk taking and creativity}

Analyzing interviews among employees, Amabile (2000) finds one of qualities that influences creativity is risk orientation. Employees who have more tendency to take risk and do things differently will have more ability to generate creativity. The author also finds that the enthusiastic managerial environment for new ideas and work conditions that employees are free from a threat of failure from the experiment are necessary conditions for creativity.

Business units lacking ability to encourage employees to creative ways may fall behind other companies. Analyzing a European technology company based in Thailand, Walter (2012) finds that working environment factors can diminish creative outcomes besides freedom and time pressure and that the main barrier to creativity is fear of risk taking. Testing hypothesis that individuals would be more creative in high risk situations than those in low risk challenges, Simmons and Ren (2009) find that there is a significant positive relationship between risk condition and individuals' creative performance. Specifically, they find that persons having less orientation of risk avoiding produce more creative outputs rather than those just accept low risk conditions.

In general, Toh and Miller (2016) find a significant positive relationship between risk taking in both financial term and creative term and creative ideas during concept selection and that this relationship is strengthened with the higher level of education. They finally highlight the fact that a person's attitude toward risk can affect his/her creative ideas generation ability and propensity for amassing creative ideas.

In a different point of view, Windels and Wilson Stuhlfaut (2014) admit individuals with greater risk taking propensity are likely to lead to greater successes and those in units with higher acceptable risk are likely to have higher creative reputations. More importantly, climate for taking risk must come up with management level first in which managers are considered as persons to take a greater risk. If so, redundant creativity or better developed creative identities will be shown out in their agencies. In sum, El-Murad and West (2003) conclude creativity with a higher level of risk taking propensity leads to 
a greater number of creative perspectives. As well, the tie between individual risk taking and creativity is positive especially if outsiders accept higher taking risk of insiders to have better performance.

\subsection{Culture, tradition and fostering creativity}

Culture is considered as a composite of all traditions, values, customs, rules, as well as economic, political and technological elements that forms activities of given societies within a given time (Ludwig, 1992). Exploring the interconnection between culture and creativity, Stein (1953) proposes that an individual with little internal freedom as grasping little tolerance for deviation or strictly following norms or rules may have less ability to generate creative development. Furthermore, the author concludes creativity must be defined and held in terms of culture in which creative things come from because they must be recognized and accepted within that socio-cultural context. Stating in the other way, it must be that culture influences on creativity and creative expression on the base of conceptualization. Regarding this relation, while measuring tradition affecting creativity in the Western, McIntyre (2008) claims cultural producers obtain specific amounts of knowledge that exist within tradition and convention of practice in creating something.

Doing a survey and analyzing data from designers in technological companies, Bye and Sohn (2010) find that sustaining work or lifestyle which promotes an environment of exploration in cultural activities is related to higher creativity levels. This process is again regarded as an important exploration on the environment that creates favorable conditions for the ability to generate new ideas. Moreover, among apparel designers with their tradition of working, these authors find that individuals with their highest creativity level usually engage much in their cultural experiences. Along with that, a lifestyle based on individuals' tradition that supports an environment to new things may be much related to higher creativity levels. In a theoretical view, Amaral Filho and Farias (2016) affirm that general development is a social process leading to ingenuity or creativity of humans. However, creativity is not stochastic and it is conditioned by cultural structures including material and immaterial forms. The material form leads creativity to material accumulation and consumption but the later one frames creativity to an individual's existential way of life. The authors mention the true relationship among development, culture and creativity and also the appearance of intervention from a state but how that state can do to dominate these ties effectively remains questionable.

One of the specialized researches between tradition and creativity by Campany (1990) which the author asserts that culture in East Asia such as in Japan and China with own traits and cultural activities has influences on modernization and development or creativity/new changes. Conjointly, this relation is two-way traffic of reintegration for mutual adjustments. More concretely, Khaleefa et al. (1996) believe in a traditional Eastern area, so-called creative individuals must know and follow their socio-cultural norms. Immerging in these criteria, these individuals may generate and possibly have more new ideas, new products and creative things than usual. Regarding tradition, creative activities aimed at the development of existing tradition is a renovation and this process can be a continuation of culture in a new form especially in the context of the Eastern region. 


\section{Methods}

\subsection{Participants}

The sample to this current research uses data from World Values Survey for SK in the latest wave, the sixth round. The dataset covers many fields for self-assessment in term of values, which manifest what human beings think and behave in their daily lives around them. Two aspects of the survey concern about the attitude and experience of individuals who recently have in their work or had job related to thinking up new ideas, subjective creativity or developing new ideas around their socio-economic environment.

Respondents of 1200 in the survey reach an average age of 43.17 (standard deviation (SD) = 14.9 ) and $49.33 \%$ of them are men. For education level, an average point is rather high compared to its median position with 7.56. The respondents owning propensity to taking risk to have an average score of $3.66(\mathrm{SD}=1.37)$. In other variables, a score of individuals working in a creative environment rather than normal routine work also gets high with $4.5(\mathrm{SD}=2.44)$.

\subsection{Measures}

\subsubsection{Creativity estimation}

Respondents have been asked in the survey to indicate if some people are very much like to not at all like them with Likert scale from one to six or ten. The main content of questions is whether it is important for a person to think up new ideas and be subjective creative to do things differently. To compatible with other variables in the increasing order, this variable is recoded differently from the original question with six as "Not at all like" respondents' choice, one as "Very much like" respondents' view. Besides, measuring new ideas, the question has been used to check directly the respondent's view with a scale from one to ten. Prototypal content has been that on the left-hand side as competition is good and it stimulates people to work hard and develop new ideas. On the other side, competition shows as harmful things and it brings out the worst for people. In line with the order of subjective creativity, the scale has been also recoded as ten which means respondents support competition and working hard to new ideas and one as competition shows less considered importance to new ideas (see more details in Table 1).

Mean values for subjective creativity and new ideas appear in Table 2 as 3.70 and 7.13 standard deviations as 1.29 and 1.98 respectively. The mean scores for creativity and new ideas are all above median points, describing that respondents in the survey advocate and towards new things in their self-estimation.

\subsubsection{Risk taking}

Asking respondents indirectly, information from the survey still keeps the nature of risk propensity of respondents as an adventure and risk taking, which are important to respondents to have an exciting life. The main content for this question mentions that some persons consider themselves very much like or not at all like them with a scale of Likert-type from one to six, in which level six has coded as very much like her/his choice. The mean score and standard deviation for this measurement are 3.66 and 1.37, respectively (see Table 2). 
Table 1. Questions in survey (source: created by authors)

\begin{tabular}{|l|l|c|}
\hline \multicolumn{1}{|c|}{ Main variables } & \multicolumn{1}{|c|}{ Survey question } & Scale \\
\hline Risk taking & Adventure and taking risks are important to have an exciting life. & $1-6$ \\
\hline Creative task & $\begin{array}{l}\text { Tasks performed at work mostly routine tasks or mostly } \\
\text { creative tasks. }\end{array}$ & $1-10$ \\
\hline Autonomy & $\begin{array}{l}\text { Independence one person has in performing tasks at work? If } \\
\text { not work currently, characterize major work in the past where } \\
1 \text { means "no independence at all" and 10 means "complete } \\
\text { independence". }\end{array}$ & $1-10$ \\
\hline Tradition & $\begin{array}{l}\text { Tradition is important to follow the customs handed down by } \\
\text { one's religion or family. }\end{array}$ & $1-6$ \\
\hline Subjective creative & $\begin{array}{l}\text { It is important to think up new ideas and be creative; to do } \\
\text { things one's own way. }\end{array}$ & $1-6$ \\
\hline New ideas & $\begin{array}{l}\text { Competition stimulates individuals to work hard and develop } \\
\text { new ideas. }\end{array}$ & $1-10$ \\
\hline
\end{tabular}

Note: Variables of tradition, creative task and new ideas are coded in the same order like other variables.

Table 2. Descriptive statistics and correlation among variables (source: created by authors)

\begin{tabular}{|c|c|c|c|c|c|c|c|c|c|c|c|c|c|}
\hline Variables & Mean & SD & Alp. & 1 & 2 & 3 & 4 & 5 & 6 & 7 & 8 & 9 & 10 \\
\hline 1. Gender & 1.51 & \begin{tabular}{|l|}
0.50 \\
\end{tabular} & 0.58 & 1 & & & & & & & & & \\
\hline 2. Age & 43.17 & 14.94 & NA. & $0.05 \dagger$ & 1 & & & & & & & & \\
\hline 3. Education & 7.56 & 1.78 & 0.51 & $-0.17^{* * *}$ & $-0.59^{* * *}$ & 1 & & & & & & & \\
\hline $\begin{array}{l}\text { 4. Risk } \\
\text { taking }\end{array}$ & 3.66 & 1.37 & 0.54 & $-0.08^{\star *}$ & $-0.26^{* * *}$ & $0.21^{\star * \star}$ & 1 & & & & & & \\
\hline $\begin{array}{l}\text { 5. Creative } \\
\text { task }\end{array}$ & 4.5 & 2.44 & 0.50 & $-0.10^{* * *}$ & $-0.16^{* * *}$ & $0.31^{\star * *}$ & $0.21^{\star * *}$ & 1 & & & & & \\
\hline 6. Income & 5.01 & 1.81 & 0.54 & $-0.05 \dagger$ & $-0.15^{\text {***}}$ & $0.33^{* * *}$ & $0.13^{\star * *}$ & $0.29^{* * *}$ & 1 & & & & \\
\hline 7. Autonomy & 5.73 & 2.36 & 0.54 & $-0.09^{\star *}$ & 0.04 & $0.13^{\star * *}$ & $0.12^{\star * *}$ & $0.43^{* * *}$ & $0.20^{* * *}$ & 1 & & & \\
\hline 8. Tradition & 3.44 & \begin{tabular}{|l|}
1.38 \\
\end{tabular} & 0.61 & -0.02 & $0.32^{* * *}$ & $-0.20^{\star \star \star}$ & $0.07^{\star *}$ & $-0.06^{\star *}$ & -0.03 & 0.03 & 1 & & \\
\hline $\begin{array}{l}\text { 9. Subjective } \\
\text { creativity }\end{array}$ & 3.70 & 1.29 & 0.53 & $-0.13^{* * *}$ & $-0.21^{* * *}$ & $0.22^{\star * *}$ & $0.48^{\star * *}$ & $0.25^{\star * *}$ & $0.10^{\star \star *}$ & $0.15^{* * *}$ & 0.04 & 1 & \\
\hline $\begin{array}{l}\text { 10. New } \\
\text { ideas }\end{array}$ & 7.13 & 1.98 & 0.59 & -0.04 & $-0.05^{\star}$ & $0.06^{*}$ & $0.11^{\star * *}$ & 0.03 & $0.05 \dagger$ & $0.13^{* * *}$ & 0.00 & $0.08^{\star}$ & 1 \\
\hline
\end{tabular}

Note: $\dagger^{*}{ }^{*},{ }^{* *}$ and ${ }^{* * *}$ denote for significant levels at $10 \%, 5 \%, 1 \%$ and $0.1 \%$ respectively. SD means standard deviation. NA stands for not available.

\subsubsection{Tradition}

Tradition in this study is a prevailing factor with a six-point Likert-type scale ranging from 1 to 6. The general temperament is that tradition is crucial for an individual to follow customs and norms handed by that individual's religion or family. Since it is more convenient to have a model in the same direction and analysis, scales have been recoded 1 as "Not at all" and respondents to 6 as "Very much". Information, content, mean value or standard deviation is more referred in Table 1 and Table 2. 


\subsubsection{Autonomy}

The popular conclusion of autonomy is from Sashkin (1982, p. 12) in which the author states "the degree to which the task provides substantial freedom, independence and discretion in scheduling the work and in determining the procedures to be used in carrying it out". Consequently, the material about independence in this survey fits for a proxy of task autonomy. The ten-point Likert-style scale of this measurement arranges for one to ten, one means "No dependence at all" and ten shows "Complete dependence".

For primary views, Figure 1 and Figure 2 display distribution and interaction among variables of tradition, risk, income and independence to subjective creative and new ideas in three dimensions. Figure 1 proves choices from respondents rather scattered and in general individuals who choose they have a propensity toward tradition at high points compared to those choose to be risky at high levels. In Figure 2, the distribution among respondents' choices is quite condensed and it is similar that a large number of individuals chooses to be independent (autonomy) that they set themselves at positions around ten in the Likert scale.
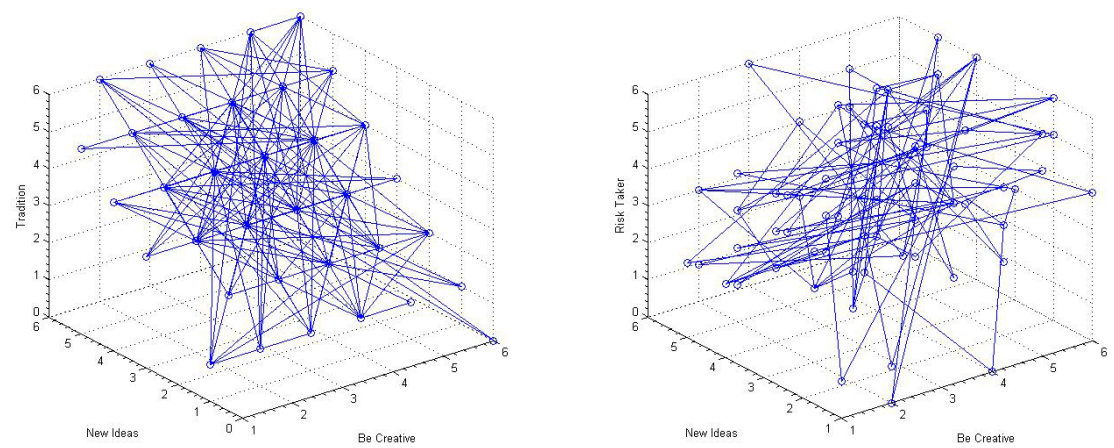

Figure 1. Three dimensions of relationships among new ideas, be creative (subjective creativity) with tradition and risk taking (source: created by authors)
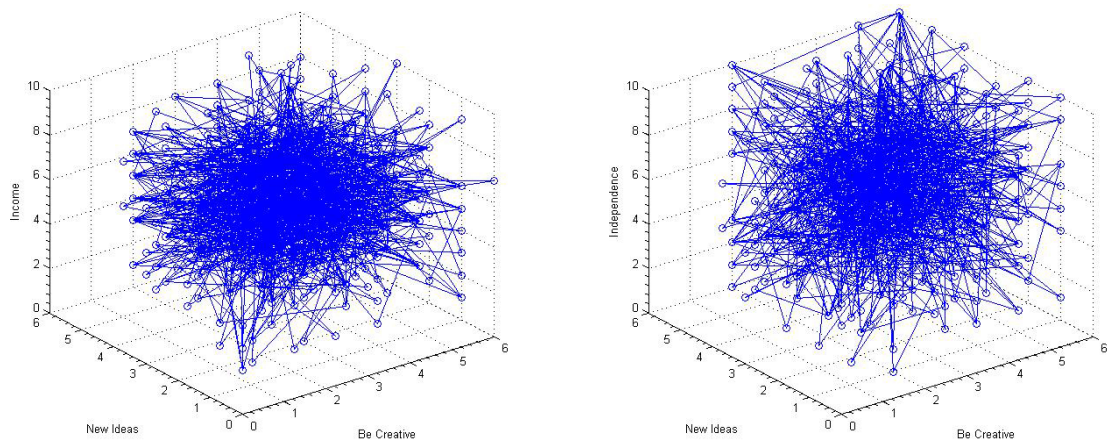

Figure 2. Three dimensions of relationships among new ideas, be creative with income and independence (autonomy) (source: created by authors) 


\section{Results}

\subsection{Correlation view}

Table 2 illustrates mean scores, standard deviations and correlations for explained and explanatory variables. Mean scores for individuals with risk taking, autonomy at work or propensity to tradition have higher values than midpoints in the rating scales while mean scores for income or creative at the task of respondents stay around midpoints or even lower than these positions.

Cronbach's alpha values and correlative significances point out ties among variables. In this study, the Cronbach's alpha values are good enough to do further analyses since they lie within the accepted range $(0.5<$ alpha $<0.6)$ while correlation values expose significantly negative or positive directions among independent variables. Individuals taking risk and adventure at tasks positively go with educational level $(\mathrm{r}=0.21, \mathrm{p}<0.01)$. As expected again, the variable of income highly significant correlates with education level, risk taking or creative task with $r$ values of $0.33,0.13$ and 0.29 , respectively. Autonomy at work has significantly and positively correlated relation with education level $(\mathrm{r}=0.13, \mathrm{p}<0.01)$, with risk taking $(\mathrm{r}=0.12, \mathrm{p}<0.01)$ and creative task $(\mathrm{r}=0.43, \mathrm{p}<0.01)$. Contrastingly, tradition is negatively correlated with education level $(r=0.20, p<0.01)$ and creative task $(r=-0.06, p<0.01)$ but positively correlated with risk taking $(\mathrm{r}=0.07, \mathrm{p}<0.01)$. On the other hand, except negatively correlated with gender and age, subjective creativity from respondents holds significantly positive correlations with educational level, risk taking, creative task, income and autonomy at $\mathrm{p}$ values all less than 0.01 . A little bit different that new ideas are positively correlated with all other explanatory variables with various significant points, risk taking $(r=0.11, p<0.01)$, autonomy $(\mathrm{r}=0.13, \mathrm{p}<0.01)$ or low significant level at $\mathrm{p}<0.1$ for income.

It is constructive if mean scores among traditional groups are shown beside comparisons or effect size values within groups of creativity and new ideas. In Table 4, means scores for traditional groups have values larger than the median points. Differences of mean points with chi-squared values checked by Kruskal-Wallis one-way analysis of variance show that the mid-ranked group of tradition in subjective creativity is different from the last group. In the same manner, the fifth group is significantly different from the last individuals in the group of new ideas while the group of traditional individuals is set as the reference group in Table 4 .

\subsection{Regression and predictors}

Ordered probit regression analysis is carried out to check interconnection among explanatory and explained factors. Demographic and main variables of creative task, risk taking, autonomy and tradition are in models to test whether these variables strongly affect subjective creativity and new ideas compared to one another one. Vitally, the variable of tradition is in the final step to discover its real influences on major trends beside control variables. Coefficient numbers, significances and chi-square values are in Table 3.

The regression models indicate that most of the interested explanatories are significantly linked with subjective creativity and new ideas with high LR chi2 at $\mathrm{p}<0.01$. In detail, in the two final full models, indicators of LR chi2 have high values with 355.39 or 37.86 . Besides, 
Table 3. Ordered probit regression exploring the relationship among variables of main variable and subjective creativity and new ideas (source: created by authors)

\begin{tabular}{|l|c|c|c|c|c|c|}
\hline \multicolumn{1}{|c|}{ Demographic variables } & \multicolumn{3}{|c|}{ Subjective creativity } & \multicolumn{3}{c|}{ New ideas } \\
\hline Gender (female) & -0.167 & -0.161 & -0.155 & -0.086 & -0.072 & -0.070 \\
& {$[0.062]^{* *}$} & {$[0.063]^{* *}$} & {$[0.063]^{* *}$} & {$[0.061]$} & {$[0.061]$} & {$[0.061]$} \\
\hline Age (log) & -0.191 & -0.248 & -0.312 & 0.010 & -0.038 & -0.040 \\
& {$[0.101]$} & {$[0.104]^{* *}$} & {$[0.108]^{* * *}$} & {$[0.099]$} & {$[0.102]$} & {$[0.105]$} \\
\hline Education & 0.055 & 0.028 & 0.030 & 0.007 & -0.001 & -0.001 \\
& {$[0.021]^{* *}$} & {$[0.023]$} & {$[0.023]$} & {$[0.020]$} & {$[0.022]$} & {$[0.022]$} \\
\hline Income & -0.011 & -0.011 & -0.012 & 0.009 & 0.009 & 0.009 \\
& {$[0.018]$} & {$[0.018]$} & {$[0.018]$} & {$[0.018]$} & {$[0.018]$} & {$[0.018]$} \\
\hline Main effect & & & & & & \\
\hline Creative task & & 0.056 & 0.056 & & -0.025 & -0.026 \\
& & {$[0.015]^{* * *}$} & {$[0.015]^{* * *}$} & & {$[0.015] \dagger$} & {$[0.015] \dagger$} \\
\hline Risk taking & & 0.366 & 0.358 & & 0.083 & 0.083 \\
& & {$[0.025]^{* * *}$} & {$[0.025]^{* * *}$} & & {$[0.023]^{* * *}$} & {$[0.024]^{* * *}$} \\
\hline Autonomy & & 0.022 & 0.021 & & 0.062 & 0.062 \\
& & {$[0.015]$} & {$[0.015]$} & & {$[0.015]^{* * *}$} & {$[0.015]^{* * *}$} \\
\hline Tradition & & & 0.050 & & & -0.003 \\
& & & {$[0.024]^{*}$} & & & {$[0.023]$} \\
\hline & & & & & & \\
\hline LR chi2 & $335.39^{* * *}$ & $352.79^{* * *}$ & $355.38^{* * *}$ & $21.39^{* * *}$ & $38.59^{* * *}$ & $37.86^{* * *}$ \\
\hline Pseudo R2 & 0.087 & 0.093 & 0.094 & 0.005 & 0.008 & 0.008 \\
\hline
\end{tabular}

Note: $\dagger^{*},{ }^{* *}$ and ${ }^{* * *}$ denote significant levels at $10 \%, 5 \%, 1 \%$ and $0.1 \%$ respectively. Values in brackets are standard errors.

Table 4. Mean scores, Kruskal-Wallis one-way analysis of variance and Cohen's $d$ (source: created by authors)

\begin{tabular}{|l|c|c|c|c|c|c|}
\hline & \multicolumn{2}{|c|}{$\begin{array}{c}\text { Mean and standard } \\
\text { deviation }\end{array}$} & \multicolumn{2}{c|}{$\begin{array}{c}\text { Kruskal-Wallis } \\
\text { (chi-squared) }\end{array}$} & \multicolumn{2}{c|}{$\begin{array}{c}\text { Effect size } \\
\text { (Cohen's } d)\end{array}$} \\
\cline { 2 - 7 } & $\begin{array}{c}\text { Subjective } \\
\text { creativity }\end{array}$ & To new ideas & $\begin{array}{c}\text { Subjective } \\
\text { creativity }\end{array}$ & To new ideas & $\begin{array}{c}\text { Subjective } \\
\text { creativity }\end{array}$ & To new ideas \\
\hline Trad 1 & $3.75(1.53)$ & $6.85(2.46)$ & 0.518 & 2.056 & 0.1254 & 0.1975 \\
\hline Trad 2 & $3.76(1.25)$ & $7.21(1.77)$ & 0.905 & 1.132 & 0.1354 & 0.0607 \\
\hline Trad 3 & $3.45(1.24)$ & $7.23(1.76)$ & $6.862^{* * *}$ & 1.016 & 0.3732 & 0.0513 \\
\hline Trad 4 & $3.70(1.20)$ & $7.20(1.93)$ & 1.809 & 0.955 & 0.1881 & 0.0635 \\
\hline Trad 5 & $3.83(1.24)$ & $6.75(2.07)$ & 0.289 & $5.386^{* *}$ & 0.0819 & 0.2639 \\
\hline Trad 6 & $3.94(1.50)$ & $7.33(2.40)$ & Control & Control & Control & Control \\
\hline
\end{tabular}

Note: Kruskal-Wallis one-way analysis of variance is for comparing average scores among groups. Cohen's $d$ shows effect size. Control denotes as the reference group.

Note: ${ }^{*}{ }^{* *}$ and ${ }^{* * *}$ denote for significant levels at $10 \%, 5 \%$ and $1 \%$ respectively. 
columns 4 and 7 provide information of goodness fit in the last two models with pseudo R2 values of 0.094 and 0.008 , respectively. The factor of risk taking among the explanatory ones has a significantly positive effect on subjective creativity and new ideas, all at very high levels $p<0.001, \beta=0.358$ and $\beta=0.083$. Controversially, the variable of the creative tasks at work has different influences where it has a positive effect on subjective creativity $(\beta=0.056$, $\mathrm{p}<0.001)$ but a negative effect on new ideas $(\beta=0.026, \mathrm{p}<0.1)$.

On the other hand, although the factor of autonomy at work has highly correlated relation with subjective creativity and new ideas $(\mathrm{r}=0.15, \mathrm{r}=0.13, \mathrm{p}<0.001)$, it can only predict the possibility of generating new ideas among respondents $(\beta=0.062, p<0.001)$. Similarly, the independent variable of income has highly correlated value with subjective creativity and new ideas but it also fails to predict these two explained factors in regression models. One more thing is that educational level can explain its effect on subjective creativity $(\mathrm{p}<0.05)$ but it fails to explain the dependent variable of new ideas when it goes with major variables and it loses significance sign. It indicates that the educational level has a less important role than major variables in explaining creativity. Finally, with coefficient value $\beta=0.050$ and significant at $\mathrm{p}<0.05$, tradition affects on creativity. It supports the hypothesis that tradition can be an exceptional factor in predicting the ability to generate subjective creativity of respondents even it is not able to predict the possibility to generating new ideas (see Table 3, columns 4 and 7).

\section{Discussion}

This empirical research aims to check the latent relationship between factors of risk taking, autonomy and tradition with subjective creativity or generating new ideas in SK. Based on Confucianism's theoretical views of rigidly conservative characteristics, South Korean people are said to have trending to avoid adventure or risk taking at work as well as they are not permitted by themselves to go far away from usual norms or rules but the finding in this research makes an interesting outcome to ignite further discussions. Risk taking is highly significantly related to both subjective creativity and attitude to new ideas, which is in line with previous studies (Baucus et al., 2008; Toh \& Miller, 2016). Being with a long tradition in the culture that it has never been faded out, perhaps South Korean individuals combine trending of risk aversion and risk taking reasonably in different specific situations to have creative outcomes and new ideas for best performance rather than solely rely on less risk taking as a normal inference from cultural perspectives. In this manner, this study suggests that individuals in this country whose propensity to be risky are likely to be in favor of new ideas and subjective creativity than those who take riskless.

In this research, with correlative links and regression models, although autonomy as risk taking has a strong correlation with both subjective creativity and attitude to new ideas, it has a highly significant influence on attitude to develop new ideas but not with subjective creativity. In previous researches, according to (Gündüz Çekmecelioğlu \& Günsel, 2011), they find that autonomy is positively and directly related to both individual creativity and job outcome. If freedom, independence and discretion of task at work provided, confidence and motivation from individuals will lead to a higher level of creativity and outcome. On the other hand, in 
one empirical research by (Shalley et al., 2000), they find that jobs high on required creativity are in line with autonomy and apparently creativity is not in the same way if highly controlled management by leadership in organizations. Due to hierarchical values from Confucian culture, South Korean individuals at work usually respect, obey and strictly follow orders from leadership or higher positioned persons in organizations and consequently individuals do not have much independence at workplaces. Individuals could provide new ideas with their autonomy or independence however, to have creative things happened they are much dependent on directions from leadership. The results show exactly the real circumstance that autonomy has a substantial influence on new ideas but not on subjective creativity. From this result, it is possible that autonomy plays certain roles in developing new ideas especially in regions and countries following the Confucian culture.

The variable of tradition is added at the end of each model to manifest how it affects and whether it interacts with other variables in relation to creativity and developing new ideas. It is normally expected that perhaps tradition in SK with long cultural values and Confucian values may "devastate" creativity or new ideas since rigid regulations and rules that do not permit changes and deviations from conventional levels. As Seo et al. (2005) say, pronounce system in Confucian culture may prevent creativity via strict gender roles, firm parent-child relationships and obedience. Withal, Kim (2007) asserts that conflicts from Confucianism that inhibit creativity, partly from education with rote learning and less playing. Secondly, a hierarchical relationship may minimize creativity via unequal relationship, rigid social structure or authoritarian relationship. Finally, benevolence in Confucianism may decrease creativity via suppression of emotion or eccentricity. Likewise, the author also suggests that more "fertile creative soil" may lead individuals to creative achievements in a base of avoiding self-evaluations of crushes to creativity from culture. In sum, it could be inferred that South Korean people still keep deserved traditional values fitting well the process of development thanks to their capabilities to generate creativity and new ideas beside elements that are named as backward values and these values could put creativity lagged behind that process. Needing to acclaim from the results, the values of tradition in the models are found to be not more extensive than autonomy, risk taking or other variables in explaining creativity in the case study.

\section{Limitations and proposed directions}

No doubt that this research has some limitations that may need to more attention in further researches. Due to the age of respondents asked in the survey ranges between 18 and over 65, information about the experience for creativity at work from young individuals or within old persons even information designed for feeling and attitude is not really manifested and fully captured in the models. Future studies should divide different groups into pre-employment, employment and post-employment groups so that interesting findings for creative contexts may be pointed out.

Secondly, adding interactions to the models could help understand relationships among factors and interactions could test the hypothesis as well as provide inferences of slope or trending among analyzed variables. Previous investigations between creativity and other variables in the informational sector with measurement of slope exactly show at the low level 
or high level of creativity how it is prompted by other variables as Richter et al. (2012). Influences of tradition interacted with autonomy and risk taking on creativity, in this research, have not mentioned testing whether the effect of this value on new ideas or subjective creativity depends on it or vice versa. As a result, further scrutiny on interactions in this matter will be useful to have more compelling findings. Next, it fails to discuss and infer why the creative task has significantly positive leverage on subjective creativity but not on new ideas. This is for certain it needs judgments for further researchers if they can utilize regional or psychological explanations beside the usual approach on socio-cultural analysis.

Finally, encouraging researches are to ones which could compare among countries complying with the heritage of Asian and Confucian culture. Possibly models encompassing Hong Kong, China, Japan and other regions could raise provocative inferences and comparisons in terms of tradition and creativity.

\section{Conclusions}

This study builds models to explain links between creative ideas and influential conditions in a country that follows Confucian tradition. Especially, this study focuses on whether culture or tradition in particular affects new things. It is hoped that the findings can shed light on the analysis between elements of tradition and creative ability in a nation.

First of all, this research finds that the variable of risk taking has significantly positive effects both on subjective creativity and on attitude to new ideas among respondents in South Korea. It implies that high level of risk taking is one of the important factors in creativity and new ideas.

Second, the results find that, despite of the fact that the factor of autonomy is positively correlative with both the attitude to new ideas and subjective creativity, it has a positive effect only on the attitude to new ideas under ordered probit regression model. Perhaps, South Korean individuals have to respect some common values at work or in society so that they just can generate new ideas for themselves but not for a bigger scale in the term of creativity.

Finally, the factor of tradition is expected to have negative effects on creativity and new ideas in prior. However, the results tell different stories. Interestingly, tradition has statically significant and positive effect on the subjective creativity. It implies that South Korea with long cultural tradition still promote rather than devastate the creativity during the development of this nation.

\section{Funding}

This work was supported by Korea Foundation's 2016 Fellowship for Field Research.

\section{References}

Amabile, T. M. (2000). A model of creativity and innovation in organizations. In B. M. Staw \& R. I. Sutton (Eds.), Research in organizational behavior, Vol. 22 (pp. 123-167). Elsevier Science, Inc.

Amabile, T. M. (1998). How to kill creativity. Harvard Business Review. https://hbr.org/1998/09/howto-kill-creativity 
Amabile, T. M., Conti, R., Coon, H., Lazenby, J., \& Herron, M. (1996). Assessing the work environment for creativity. The Academy of Management Journal, 39(5), 1154-1184. https://doi.org/10.2307/256995

Amaral Filho, do J., \& Farias, D. B. L. (2016). Celso furtado: culture and creativity matter. Journal of Economic Issues, 50(2), 444-451. https://doi.org/10.1080/00213624.2016.1176508

Baucus, M. S., Norton, W. I. Jr., Baucus, D. A., \& Human, Sh. E. (2008). Fostering creativity and innovation without encouraging unethical behavior. Journal of Business Ethics, 81, 97-115. https://doi.org/10.1007/s10551-007-9483-4

Brindley, D. L. (2008). Culture, creativity, and research. New Review of Academic Librarianship, 14(1-2), 17-35. https://doi.org/10.1080/13614530802518867

Bye, E., \& Sohn, M. (2010). Technology, tradition, and creativity in apparel designers: a study of designers in three US Companies. Fashion Practice, 2(2), 199-222. https://doi.org/10.2752/175693810X12774625387477

Campany, R. F. (1990). Tradition and creativity: essays on East Asian Civilization by Ching-I Tu. The Journal of Religion, 70(2), 298-299. https://doi.org/10.1086/488390

Chang, J. W., Huang, D. W., \& Choi, J. N. (2012). Is task autonomy beneficial for creativity? Prior task experience and self-control as boundary conditions. Social Behavior and Personality: An International Journal, 40(5), 705-724. https://doi.org/10.2224/sbp.2012.40.5.705

Cho, R. L. T., Liu, J. S., \& Ho, M. H.-Ch. (2018). What are the concerns? Looking back on 15 years of research in cultural and creative industries. International Journal of Cultural Policy, 24(1), 25-44. https://doi.org/10.1080/10286632.2015.1128417

DiLiello, T. C., \& Houghton, J. D. (2006). Maximizing organizational leadership capacity for the future: toward a model of self-leadership, innovation and creativity. Journal of Managerial Psychology, 21(4), 319-337. https://doi.org/10.1108/02683940610663114

El-Murad, J., \& West, D. C. (2003). Risk and creativity in advertising. Journal of Marketing Management, 19(5-6), 657-673. https://doi.org/10.1080/0267257X.2003.9728230

Gündüz Çekmecelioğlu, H., \& Günsel, A. (2011). Promoting creativity among employees of mature industries: the effects of autonomy and role stress on creative behaviors and job performance. Procedia: Social and Behavioral Sciences, 24, 889-895. https://doi.org/10.1016/j.sbspro.2011.09.020

Khaleefa, O. H., Erdos, G., \& Ashria, I. H. (1996). Creativity in an indigenous Afro-Arab Islamic culture: the case of Sudan. Journal of Creative Behavior, 30(4), 268-282. https://doi.org/10.1002/j.2162-6057.1996.tb00773.x

Kim, K. H. (2007). Exploring the interactions between Asian culture (Confucianism) and creativity. Journal of Creative Behavior, 41(1), 28-53. https://doi.org/10.1002/j.2162-6057.2007.tb01280.x

Kristeller, P. O. (1983). "Creativity" and "Tradition". Journal of the History of Ideas, 44(1), 105-113. https://doi.org/10.2307/2709307

Ludwig, A. M. (1992). Culture and creativity. American Journal of Psychotherapy, 46(3), 454-469. https://doi.org/10.1176/appi.psychotherapy.1992.46.3.454

McIntyre, Ph. (2008). Creativity and cultural production: a study of contemporary Western popular music songwriting. Creativity Research Journal, 20(1), 40-52. https://doi.org/10.1080/10400410701841898

Murphy, A. B. (2012). China's cultural and creative economy: an introduction. Eurasian Geography and Economics, 53(2), 179-181. https://doi.org/10.2747/1539-7216.53.2.179

Richter, A. W., Hirst, G., Knippenberg, van D., \& Baer, M. (2012). Creative self-efficacy and individual creativity in team contexts: cross-level interactions with team informational resources. Journal of Applied Psychology, 97(6), 1282-1290. https://doi.org/10.1037/a0029359

Rinne, T., Steel, G. D., \& Fairweather, J. (2013). The role of Hofstede's individualism in national-level creativity. Creativity Research Journal, 25(1), 129-136. https://doi.org/10.1080/10400419.2013.752293 
Sashkin, M. (1982). Work redesign. J. R. Hackman and G. R. Oldham Reading, MA: Addison-Wesley, 1980, xxvii +330 pp. Group and Organization Management, 7(1), 121-124. https://doi.org/10.1177/105960118200700110

Schwartz, Sh. H. (1999). A theory of cultural values and some implications for work. Applied Psychology, 48(1), 23-47. https://doi.org/10.1111/j.1464-0597.1999.tb00047.x

Seo, H.-A., Lee, E. A., \& Kim, K. H. (2005). Korean science teachers' understanding of creativity in gifted education. Journal of Advanced Academics, 16(2-3), 98-105. https://doi.org/10.4219/jsge-2005-476

Simmons, A. L., \& Ren, R. (2009). The influence of goal orientation and risk on creativity. Creativity Research Journal, 21(4), 400-408. https://doi.org/10.1080/10400410903297980

Shalley, Ch. E., Gilson, L. L., \& Blum, T. C. (2000). Matching creativity requirements and the work environment: effects on satisfaction and intentions to leave. The Academy of Management Journal, 43(2), 215-223. https://doi.org/10.5465/1556378

Stein, M. I. (1953). Creativity and culture. The Journal of Psychology, 36(2), 311-322. https://doi.org/10.1080/00223980.1953.9712897

Toh, Ch. A., \& Miller, S. R. (2016). Choosing creativity: the role of individual risk and ambiguity aversion on creative concept selection in engineering design. Research in Engineering Design, 27, 195-219. https://doi.org/10.1007/s00163-015-0212-1

Volmer, J., Spurk, D., \& Niessen, C. (2012). Leader-Member Exchange (LMX), job autonomy, and creative work involvement. The Leadership Quarterly, 23(3), 456-465. https://doi.org/10.1016/j.leaqua.2011.10.005

Walter, Ch. (2012). Work environment barriers prohibiting creativity. Procedia: Social and Behavioral Sciences, 40, 642-648. https://doi.org/10.1016/j.sbspro.2012.03.243

Wang, A.-Ch., \& Cheng, B.-Sh. (2010). When does benevolent leadership lead to creativity? The moderating role of creative role identity and job autonomy. Journal of Organizational Behavior, 31(1), 106-121. https://doi.org/10.1002/job.634

Windels, K., \& Wilson Stuhlfaut, M. (2014). Confined creativity: the influence of creative code intensity on risk taking in advertising agencies. Journal of Current Issues and Research in Advertising, 35(2), 147-166. https://doi.org/10.1080/10641734.2014.899530 